\title{
Anterior Versus Posterior Decompression for Symptomatic Spinal Metastasis
}

\author{
R.G. Perrin and R.J. McBroom
}

\begin{abstract}
Management of patients with symptomatic spinal metastasis is designed to (1) relieve pain, and (2) restore or preserve neurologic function. The surgical strategy must include provisions for decompression of the dural sac and nerve roots, and stabilization of the spinal column. The optimal surgical approach, whether from in front or from behind is determined by a number of factors including (1) tumour location, (2) spinal level, (3) fixation factors, (4) patient debility.
\end{abstract}

\begin{abstract}
RÉSUMÉ: Décompression antérieure versus décompression postérieure dans le cas de métastases spinales symptomatiques Le traitement des patients présentant des métastases spinales vise essentiellement 1) à soulager la douleur et 2) à restorer ou à préserver la fonction nerveuse. La manoeuvre chirurgicale doit prévoir la décompression du sac dural et des racines nerveuses et la stabilisation de l'épine dorsale. La meilleure approche chirurgicale, qu'elle soit antérieure ou postérieure, est déterminée par un certain nombre de facteurs dont 1) la localisation de la tumeur; 2) son niveau; 3) les éléments de fixation; 4) l'état de débilité du patient.
\end{abstract}

Can. J. Neurol. Sci. 1987: 14:75-80

Controversy concerning the management of patients with symptomatic spinal metastasis has focussed firstly on the relative merits of radiation ${ }^{1.2 .3 .4}$ and surgery ${ }^{5.6 .7 .8 .9,10.11}$ (or a combination of these treatment modalities $12.13,14,15,16,17$ ) and secondly on the optimal approach (decompression from behind $8,14,18,19.20$ or from in front ${ }^{9.21 .22 .23 .24}$ ) in those patients selected for surgical treatment.

It has been our practice to regard radiation therapy as the initial treatment of choice and to consider surgical decompression: (1) when radiation therapy fails, (2) if the diagnosis of the extradural compressing lesion is in doubt, (3) in patients with pathological fracture dislocation, and (4) when rapidly evolving or far advanced paraplegia has occurred.

Our initial efforts in the management of patients with symptomatic spinal metastasis involved posterior decompression procedures. ${ }^{7,8,14,20,25}$ More recently we have accumulated a series of patients with symptomatic spinal metastasis treated by anterior decompression procedures. The purpose of this paper is to summarize our experience with anterior and posterior approaches, and to examine factors which determine the optimal surgical strategy for the treatment of patients with symptomatic spinal metastasis.

\section{MATERIALS AND MethodS}

\section{(a) Posterior Decompression}

Previous reports have detailed our series of patients man- aged by posterolateral decompression of the dural sac and nerve roots. ${ }^{8.14 .20 .25}$ There were 200 consecutive cases, including 86 men and 114 women, ranging in age from 21 to 80 years. Culpable primaries originated most commonly from breast followed by prostate and lung; the origin of spinal metastasis was unknown in $9 \%$ of patients (Table 1). Clinically, pain was the earliest and most prominent feature in 174 patients $(87 \%)$. Preoperative motor testing revealed full power (Grade 5/5) in 10 cases $(5 \%), 64$ patients ( $32 \%$ ) were classified as weak but ambulatory (Grade 4/5), 102 (51\%) were bedridden (Grade 1-3/5) and $24(12 \%)$ were frankly paraplegic (no clinically detectable voluntary movement). Sphincter dysfunction was recorded for 86 patients (43\%), (Table 2).

Radiographic abnormalities were documented in all patients. The most common plain film finding was pedicle erosion ("winking owl sign", Figure 1). Myelography most often demonstrated a complete block at the site of spinal cord compression, and when the clinical and myelographic levels were incongruous, or, when we suspected multiple levels of involvement, then cisternal myelography was also carried out to more accurately delineate the extent of disease (Figure 2).

The posterior surgical approach involved a wide laminectomy extending for half a level above and half a level below the compressing lesion, and with decompression of the dural sac to beyond its equator. Most commonly, the tumour-destroyed lateral elements were resected posterolaterally permitting access 
to the vertebral body. More anteriorly situated tumour could thus be removed until circumferential decompression of the dural sac and nerve roots was achieved.

Spinal stabilization was carried out using a variety of fixation devices including autologous rib graft, methylmethacrylate struts, Harrington instrumentation, and Luque rods (Figure 3 ). ${ }^{8}$

\section{RESULTS}

One hundred and fifty-nine patients $(80 \%)$ reported pain relief following posterolateral decompression. One hundred and thirtyone patients $(65 \%)$ walked postoperatively, compared to 74 (37\%) who were walking preoperatively. Eight patients (4\%) were worse. Fifteen patients died within $\mathbf{3 0}$ days of surgery giving an operative mortality rate of $8 \%$. Eighty-four patients (42\%) achieved a "satisfactory result", ie. they were walking and continent 6 months following surgery (Table 3 ).

Table 1: Culpable primaries among 200 consecutive patients treated by posterolateral decompression

\begin{tabular}{ccc}
\hline \multicolumn{3}{c}{ POSTERIOR DECOMPRESSION } \\
primary: & Breast & 62 \\
& Prostate & 20 \\
& Lung & 17 \\
Lymph & 15 \\
GI & 14 \\
& GYN & 13 \\
Sarcoma & 12 \\
Kidney & 8 \\
& Skin & 7 \\
Nasoph. & 5 \\
& Thyroid & 4 \\
& Bladder & 3 \\
& Parotid & 2 \\
& $?$ & 18 \\
& & 200 \\
&
\end{tabular}

Table 2: Clinical features among 200 consecutive patients prior to posterolateral decompression. The numbers in brackets indicate muscle strength on a 0-5 grading scale

\begin{tabular}{|c|c|c|c|c|}
\hline \multicolumn{5}{|c|}{$\begin{array}{l}\text { SPINAL METASTASIS } \\
\text { (Posterior Decompression) }\end{array}$} \\
\hline clinical: & pain: & $87 \%$ & & \\
\hline & motor: & $\begin{array}{r}5 \% \\
32 \% \\
51 \% \\
12 \%\end{array}$ & $\begin{array}{l}\text { normal } \\
\text { weak } \\
\text { bedridden } \\
\text { paraplegic }\end{array}$ & $\begin{array}{r}(4 / 5) \\
(1-3 / 5) \\
(0 / 5)\end{array}$ \\
\hline
\end{tabular}

Table 3: Postoperative status of 200 consecutive patients following posterolateral decompression for extradural spinal metastasis

\begin{tabular}{llr}
\hline \hline & SPINAL METASTASIS \\
results: & (Posterior Decompression) & \\
& pain relief: & $80 \%$ \\
& motor: ambulatory & $65 \%$ \\
& improved & $17 \%$ \\
& unchanged & $14 \%$ \\
& worse & $4 \%$ \\
& mortality (30 days) & $8 \%$ \\
& "satisfactory result" & $42 \%$ \\
\hline
\end{tabular}

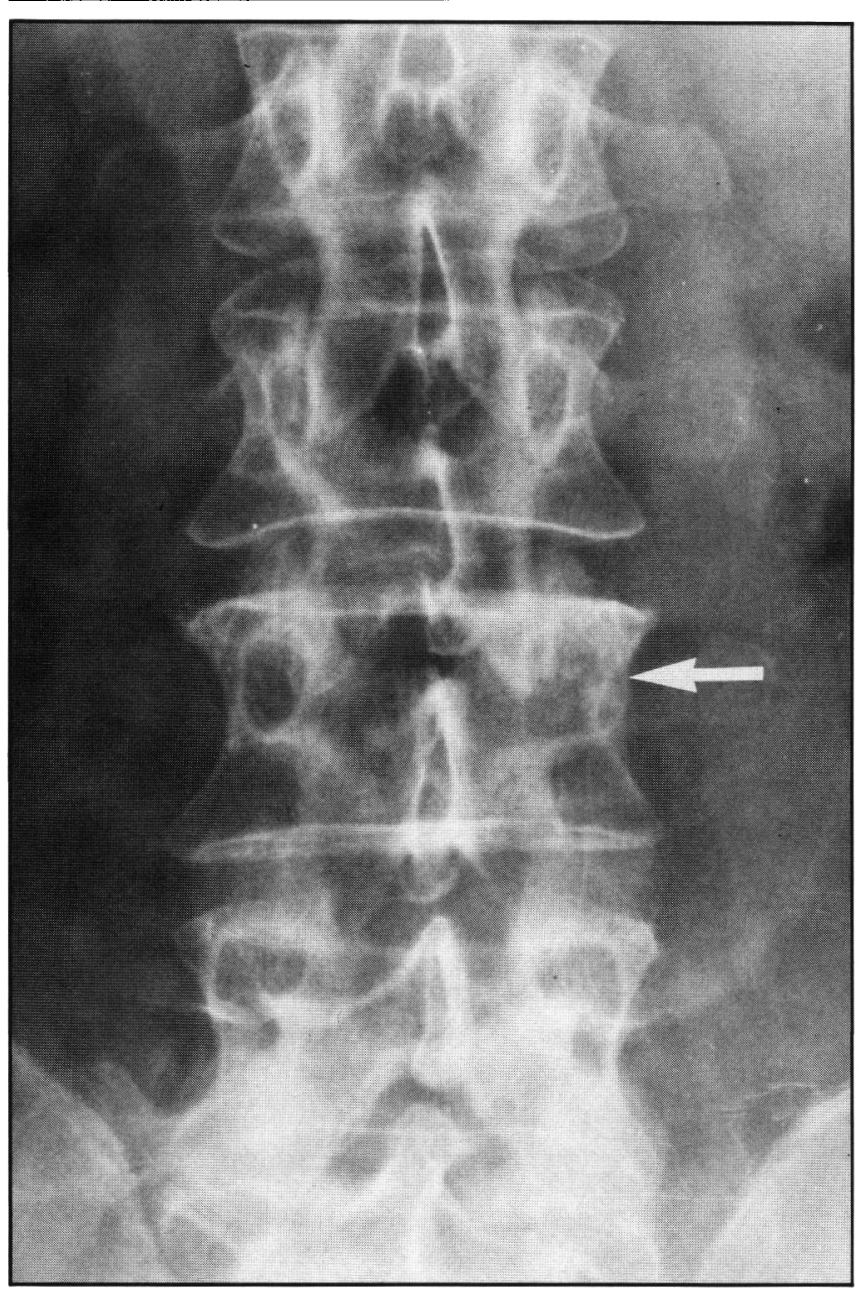

Figure I - AP Radiograph of lumbar spine showing pedicle erosion (arrow) ("Winking Owl Sign'),

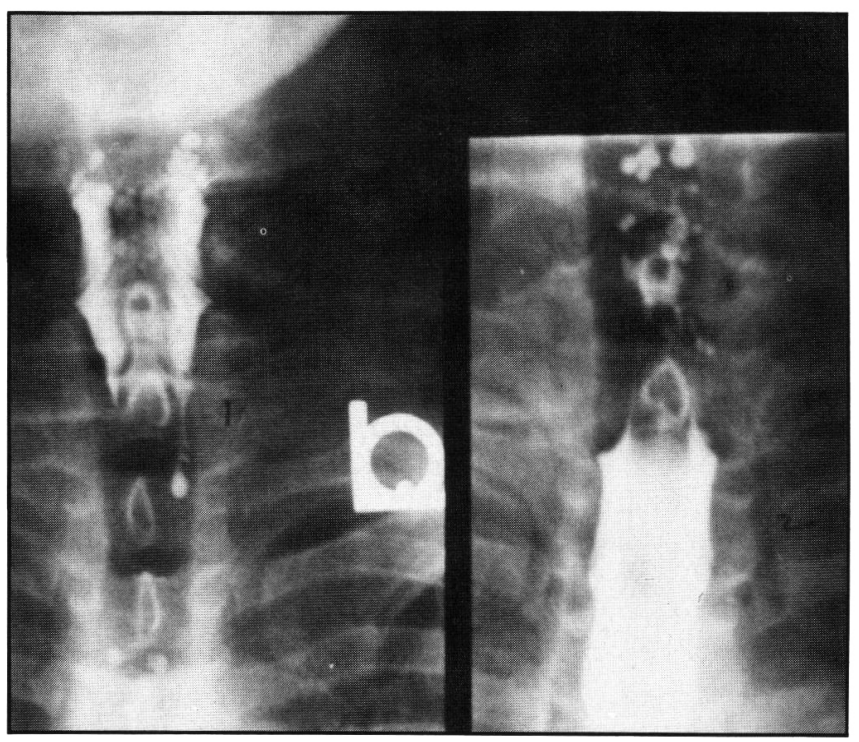

Figure 2 - Lumbar myelograph showing complete block from below (right photograph) and cisternal myelograph showing complete block from above (left photograph), to delineate the extent of the extradural compressing lesion. 


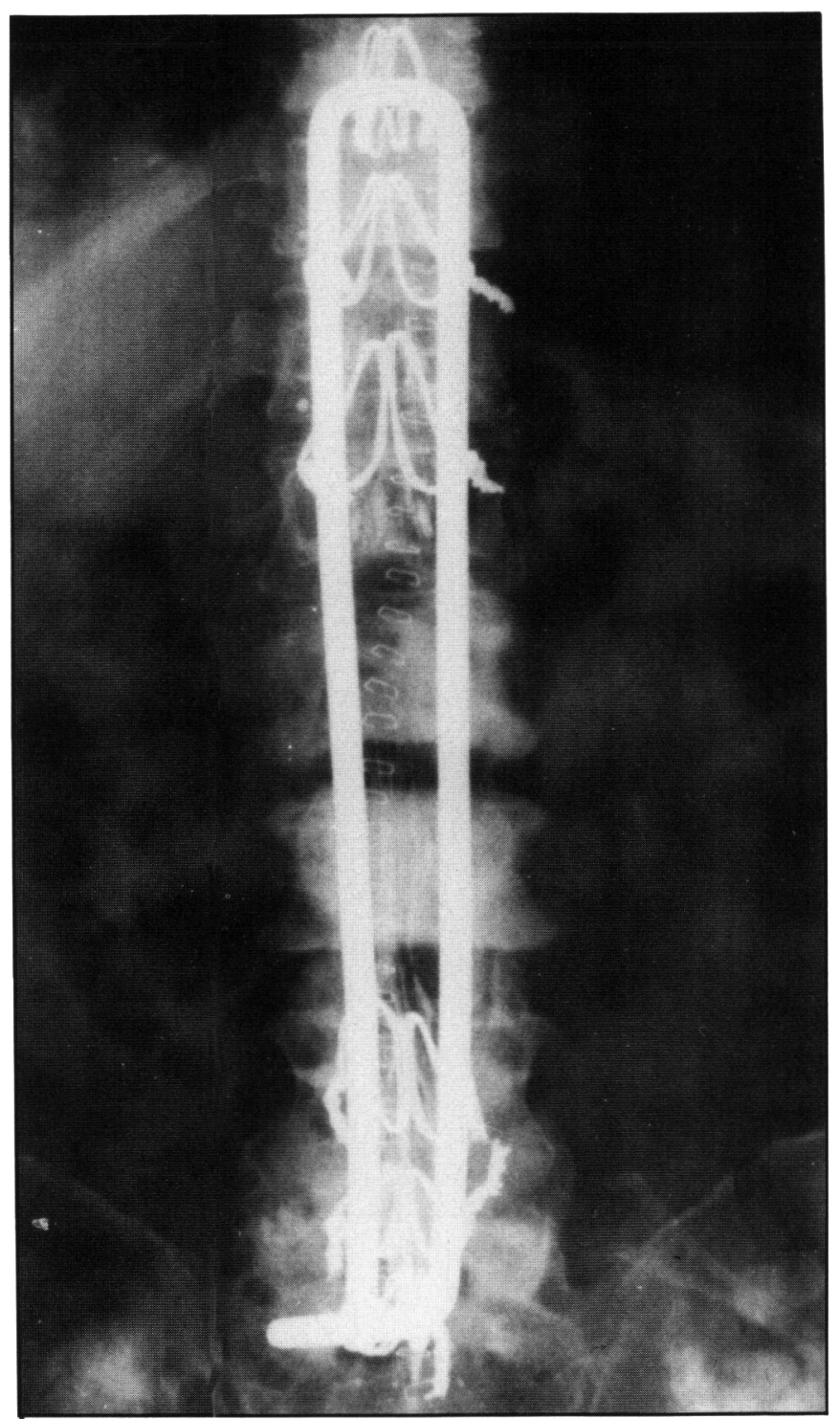

Figure 3 - Luque rod fixation in place following posterolateral decompres. sion at $L 2,3$.

\section{(b) Anterior Decompression}

Twenty-one patients were treated with anterior decompression and stabilization. This group included 7 men and 14 women ranging in age from 39 to 73 years. The most common culpable primary originated in breast (38\%) followed by lung (29\%) and kidney $(9.5 \%)$. In 2 cases $(9.5 \%)$ the primary was unknown (Table 4).

Preoperative motor assessment is summarized in Table 5. Four patients (19\%) demonstrated full power. Four patients (19\%) were weak but ambulatory, 11 patients $(52 \%)$ were bedridden, and 2 patients $(9.5 \%$ ) were frankly paraplegic (no clinically detectable voluntary motor function).

Lumbar myelography most often demonstrated a complete block to contrast. When the clinical and lumbar myelographic levels were incongruous or when multiple levels of disease were suspected, then cisternal myelography was also carried out to define the extent of the spinal involvement. The distribution of symptomatic spinal metastasis in this group included: cervical spine 5 cases (19\%), thoracic segments 14 cases $(67 \%)$, and lumbar levels 2 cases $(9.5 \%)$.
Anterior decompression of the dural sac and nerve roots required resection of the major portion of an involved vertebral body (Figure 4). Adequate anterior decompression necessitated resection at two contiguous vertebral bodies in 6 patients.

Stabilization was provided by a stainless steel plate contoured to size with dimensions determined intraoperatively to fit the decompression defect and fixed in place with fully threaded cancellous screws. Methylmethacrylate, moulded to fill the bracketed defect, was inspissated through the holes in the plate to hold the acrylic in place (Figure 4).

\section{RESULTS}

Nineteen patients $(90 \%)$ reported pain relief. Sixteen $(76 \%)$ were ambulatory following surgery, compared to $8(38 \%)$ who were walking preoperatively. One patient $(5 \%)$ was worse after anterior decompression and stabilization (Table 6).

\section{Discussion}

Symptomatic spinal metastasis represents a serious complication of systemic cancer. The clinical presentation begins, in about $90 \%$ of patients, with local back or neck pain. Tenderness to percussion over the involved vertebrae is usually present. A radicular pain syndrome may be evident - with or without segmental spinal pain and tenderness. Characteristically, pain

Table 4: Culpable primaries among 21 consecutive patients treated with anterolateral decompression

\begin{tabular}{clc}
\hline \multicolumn{2}{c}{ ANTERIOR DECOMPRESSION } \\
primary: & Breast & 8 \\
& Kidney & 6 \\
& Prostate & 2 \\
& Lung & 1 \\
& Ovary & 1 \\
& Uterus & 1 \\
& $?$ & 2 \\
& & 21 patients \\
& &
\end{tabular}

Table 5: Clinical features among 21 consecutive patients prior to anterolateral decompression

\begin{tabular}{llclr}
\hline \hline & & \multicolumn{2}{c}{ SPINAL METASTASIS } \\
(Anterior Decompression) & \\
clinical: & pain: & $100 \%$ & & \\
& motor: & $19 \%$ & normal & \\
& & $19 \%$ & weak & $(4 / 5)$ \\
& & $52 \%$ & bedridden & $(1-3 / 5)$ \\
& & $9 \%$ & paraplegic & $(0 / 5)$ \\
\hline
\end{tabular}

Table 6: Postoperative status of 21 consecutive patients following anterolateral decompression for extradural spinal metastasis

\begin{tabular}{llr}
\hline & SPINAL METASTASIS & \\
results: & (Anterior Decompression) & \\
& pain relief: & $90 \%$ \\
& motor: ambulatory & $76 \%$ \\
& improved & $19 \%$ \\
& worse & $5 \%$ \\
& mortality (30 days) & $5 \%$ \\
& "satisfactory result" & $33 \%$ \\
\hline
\end{tabular}




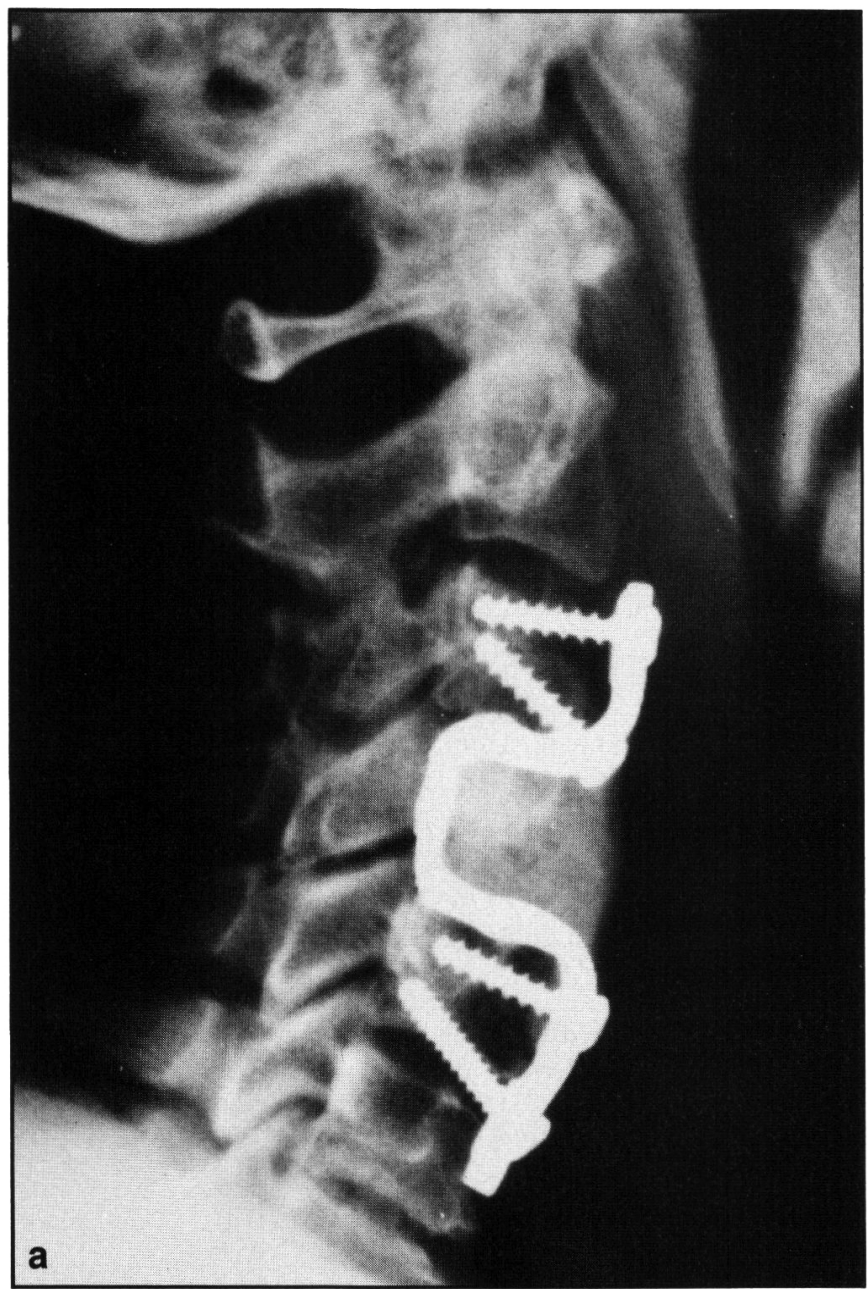

Figure 4 - Stabilization apparatus in place following anterolateral decompression at cervical (4a) and thoracic (4b) spinal segments.

is followed by weakness, sensory loss and sphincter dysfunction, all of which will progress relentlessly to complete an irreversible paraplegia unless timely treatment is undertaken.

Surgical intervention for symptomatic spinal metastasis is designed to relieve pain and preserve or restore neurologic function. Treatment is essentially palliative. Nevertheless, relief from pain and preservation or restoration of neurologic function contributes immeasurably to the quality of remaining life.

Current controversy concerning the surgical management of patients with symptomatic spinal metastasis is focussed on the most appropriate surgical approach, ie. decompression from in front ${ }^{9,21,22,23,24}$ or from behind. ${ }^{8,14,18,19.20}$ Critics of posterior decompression procedures point out (and correctly so) that simple laminectomy is inadequate..$^{9,21,22.23 .24}$ They point out that the compressing tumour is largely anterior or anterolateral and then conclude, incorrectly, that anteriorly disposed spinal metastasis must be removed from in front (Figure 5a). ${ }^{4.21 .22,23,24}$

The surgical approach from behind with wide laminectomy and posterolateral exposure of the dural sac has been shown to result in effective decompression of the spinal cord and nerve roots. ${ }^{8.14,18.19}$ This approach most often includes resection of the tumour-destroyed lateral elements and thus provides access to the anterior aspect of the dural sac allowing extensive and circumferential decompression of the dural sac and nerve roots (Figure 5b).

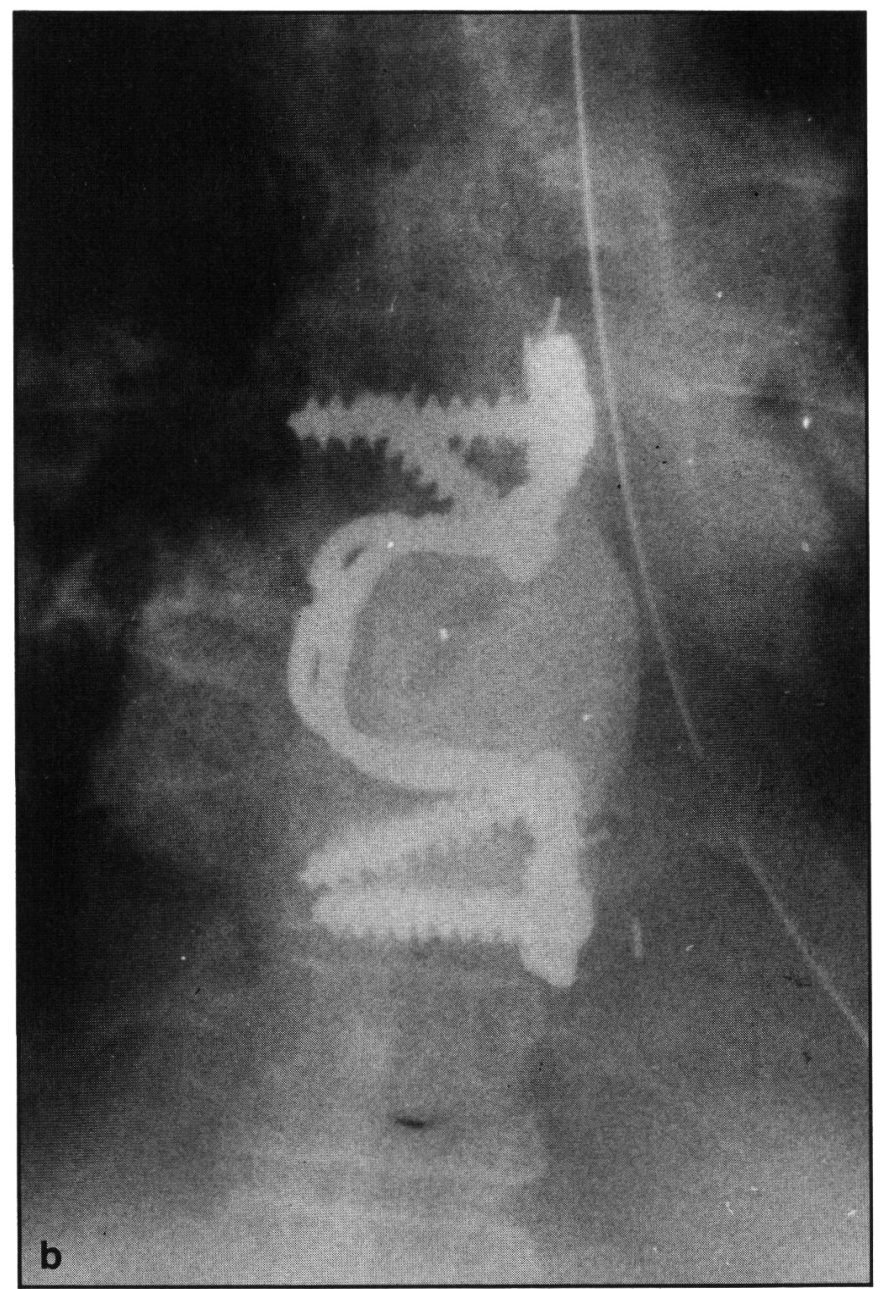

The anterolateral approach involves resecting the major portion of an involved vertebral body and has been reported to permit effective removal of anteriorly situated epidural tumour. 9,21,22,23,24 Circumferential decompression of the dural sac and nerve roots bilaterally is, however, rarely possible due to limited access around the dural sac from the anterolateral approach (Figure 5c).

It has been our clinical impression that pain relief achieved following anterior decompression and stabilization may be superior to that obtained following posterolateral procedures. To draw further conclusions from the results of the retrospective analyses we have reported would be erroneous. Rather, the benefit of our experience with both posterior and anterior approach for the treatment of symptomatic spinal metastasis lies in the distillation of factors which must be considered and which serve as guidelines in determining the appropriate surgical strategy as outlined below (Table 7).

\section{(1) Tumour Location}

It has been our observation that in the large majority of patients with symptomatic spinal metastasis the dura is compressed by tumour mass that is located lateral to it, often anterolateral, but lateral nonetheless. It is uncommon for an epidural metastasis causing cord compression to be exclusively anterior, and rarely is the metastasis exclusively posterior to 


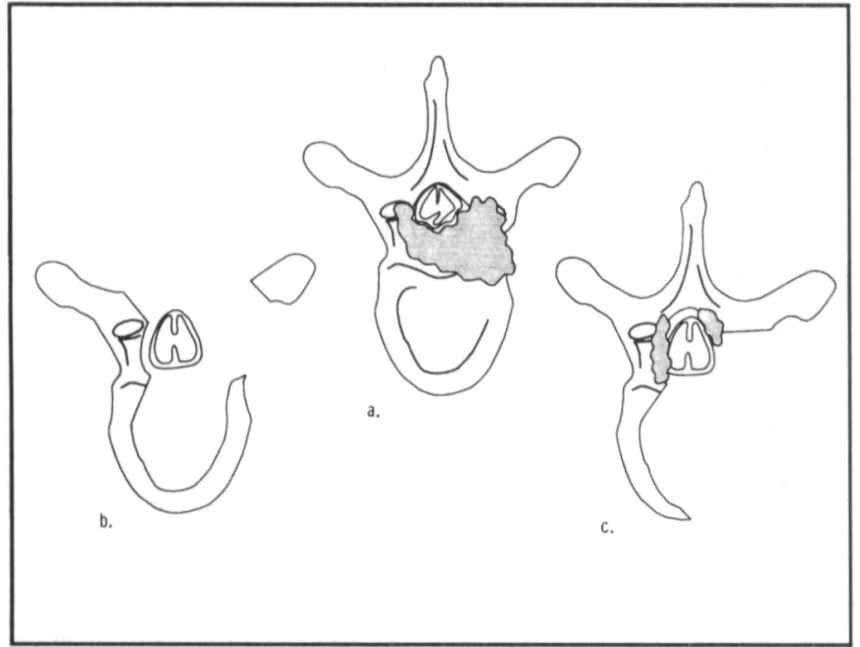

Figure 5 - Diagrammatic representation of extradural spinal metastasis causing spinal cord compression (5a). Posterolateral approach permits circumferential decompression of the dural sac and its contents $(5 b)$. Anterolateral approach allows effective removal of anteriorly situated epidural tumour, however, circumferential decompression of the dural sac and nerve roots bilaterally is rarely possible $(5 c)$.

Table 7: Factors to be considered and which serve as guidelines in determining the appropriate surgical strategy (anterior versus posterior approach)

\begin{tabular}{ll}
\hline \hline & \multicolumn{1}{c}{ SPINAL METASTASIS } \\
(Ant. vs Post. Decompression)
\end{tabular}

the dural sac. Frequently, however, the tumour may extend around the circumference of the dural sac. In our experience, the posterolateral approach will permit a very thorough tumour resection, allowing its removal circumferentially about the dural sac and about nerve roots bilaterally. Such radical resection and circumferential decompression is less likely to be achieved by an anterolateral approach.

\section{(2) Spinal Level}

Anterior decompression procedures for metastatic disease are rarely appropriate at the extreme ends of the spinal column. Apart from the difficulties and challenge posed by anterior approaches for decompression at the craniocervical and lumbosacral junctions, anterior spinal stabilizations at these levels pose enormous technical problems.

\section{(3) Fixation Factors}

Effective posterolateral decompression of the dural sac and its contents frequently renders the spine unstable, and necessitates fixation of the spinal column. It has been our experience that posterior decompression procedures performed through an irradiated field and which are followed by spinal stabilization have been associated with a high incidence of wound dehiscence (with or without infection). In a series of 33 consecutive patients treated with posterolateral decompression followed by Luque rods stabilization, wound breakdown occurred in $24 \%$ of patients. ${ }^{26}$ Contributing factors to this high complication rate include a radiated field, use of high dose steroids, systemic debilitation of the patient, as well as the lengthy operative procedure with installation of bulky stabilization apparatus.

Stabilization from in front is not practical if more than two spinal segments are decompressed. Furthermore, secure stabilization relies on sufficient bony integrity at levels adjacent to the decompression site to accept fixation devices.

\section{(4) Patient Debility}

The patient may be too sick systemically to tolerate an anterior transthoracic or thoracoabdominal decompression procedure which is a much more formidable undertaking than the posterior approach.

\section{ConClusion}

Successful surgical management of patients with symptomatic spinal metastasis requires not only decompression of the spinal cord and nerve roots, but must also provide for stability of the spinal column. Based on our experiences with approaches from behind and from in front, a variety of factors determine the most appropriate surgical strategy. No single approach is always applicable and the treatment team must be prepared to execute the optimal approach.

\section{ACKNOWLEDGEMENTS}

The authors wish to thank Judy Dinsdale for her secretarial assistance.

\section{REFERENCES}

1. Black P. Spinal metastasis: current status and recommended guidelines for management. Neurosurgery 1979; 5: 726-745.

2. Dunn RC, Jr., Kelly WA, Wohns RN, Howe JF. Spinal epidural neoplasia: A 15 year review of the results of surgical therapy. J Neurosurg 1980; 52: 47-51.

3. Friedman M, Kim TH, Panahon A. Spinal cord compression in malignant lymphoma: treatment and results. Cancer 1976; 37: 1485-91.

4. Gilbert RW, Kim J-H, Posner JB. Epidural spinal cord compression from metastatic tumour: diagnosis and treatment. Ann Neurol 1978; 3: 40-51.

5. Alexander B, Davis $\mathrm{CH}$, Field CH. Metastatic lesions of the vertebral column causing cord compression. Neurology 1956; 6: 103-107.

6. Benson WJ, Scarffe HH, Todd IDH. Spinal cord compression in myeloma. Brit Med J 1979; 1: 1541-1544.

7. Bogoch ER, English E, Perrin RG, Tator $\mathrm{CH}$. Successful surgical decompression of spinal extradural metastases of liposarcoma. Spine 1983; 8: 228-235.

8. Perrin RG, Livingston KE. Neurosurgical treatment of pathological fracture-dislocation of the spine. J Neurosurg 1980;52:330-4.

9. Sundaresan N, Galicich J, Bains M, Martini N, Beattie EJ. Vertebral body resection in the treatment of cancer involving the spine. Cancer 1984; 53: 1393-1396.

10. Wilson CB, Fewer D. Role of neurosurgery in the management of patients with carcinoma of the breast. Cancer 1971: 28: 1681-5.

11. Wright RL. Malignant tumors in the spinal extradural space. Annals of Surgery 1963; 157: 227-231.

12. Brady LW, et al. The treatment of metastatic disease of the nervous system by radiation therapy. In: Seydel HG, ed. Tumours of the nervous system. New York: John Wiley \& Sons, 1975: 177-188.

13. Brice J, McKissock W. Surgical treatment of malignant extradural spinal tumours. Brit Med J 1965; 1: 1341-1344. 
14. Livingston KE, Perrin RG. Neurosurgical management of spinal metastastes. J Neurosurg 1978; 49: 839-843.

15. Marshall LF, Langfitt TW. Combined therapy for metastatic extradural tumors of the spine. Cancer 1977; 40: 2067-2070.

16. White WA, Patterson RH, Bergland RM. Role of surgery in the treatment of spinal cord compression by metastatic neoplasm. Cancer 1971; 3: 558-61.

17. Wild WO, Porter RW. Metastatic epidural tumor of the spine. Arch Surg 1963; 87: 825-30.

18. Arbit E, Brem S, Rubenstein A. A surgical approach through the pedicle to metastatic tumours of the spine. Presented at the 8th International Congress of Neurological Surgery, Toronto, July 7-13, 1986.

19. Garrido E. Modified costotransversectomy: a surgical approach to ventrally placed lesions in the thoracic spinal canal. Surg Neurol 1980: 13: 109-113.

20. Perrin RG, Livingston KE. Pathological fracture-dislocation of the cervical spine. $I n$ : Tator $\mathrm{CH}$, ed. Early Management of Acute Spinal Cord Injury. New York: Raven Press, 1982: 365-372.
21. Harrington KD. Anterior decompression and spinal stabilization for patients with metastatic lesions of the spine. J Neurosurg 1984; 61: 107-117.

22. Harrington KD. The use of methyl methacrylate for vertebralbody replacement and anterior stabilization of pathological fracturedislocations of the spine due to metastatic malignant disease. $J$ Bone Joint Surg (Am) 1981; 63: 36-46.

23. Siegal T, Siegal T. Surgical decompression of anterior and posterior malignant epidural tumors compressing the spinal cord: a prospective study. Neurosurg 1985; 17: 424-431.

24. Siegal T, Siegal T, Robin G, Lubetzki-Korn I, Fuks Z. Anterior decompression of the spine for metastatic epidural cord compression. Ann Neurol 1982; 11: 28-34.

25. Perrin RG, Livingston KE, Aarabi B. Intradural extramedullary spinal metastasis. J Neurosurg 1982; 56; 835-837.

26. Heller M, Perrin RG, Macnab I, McBroom RJ. Posterolateral decompression and Luque instrumentation for metastatic disease of the spine. J Neuroorthopaedics (In Press) 1986. 